\title{
Psychrotrophic bacteria in milk: How much do we really know?
}

\author{
Gislene B. de Oliveira ${ }^{1}$, Luciana Favarin ${ }^{1}$, Rosa H. Luchese ${ }^{1}$, Douglas McIntosh ${ }^{2}$ \\ ${ }^{1}$ Ciência e Tecnologia de Alimentos, Universidade Federal Rural do Rio de Janeiro, \\ Seropédica, RJ, Brazil. \\ ${ }^{2}$ Parasitologia Veterinária, Universidade Federal Rural do Rio de Janeiro, Seropédica, RJ, Brazil.
}

Submitted: September 9, 2013; Approved: December 19, 2014.

\begin{abstract}
The occurrence of psychrotrophic bacteria in raw milk is studied worldwide due to the difficulties associated with controlling their growth during cold storage and the consequent negative effects upon fluid milk or dairy products. Among the psychrotrophic bacteria, the genus Pseudomonas (represented primarily by $P$. fluorescens) has been highlighted as the cause of numerous defects in dairy products. In light of its perceived predominance, this species has frequently been chosen as a model organism to assess the effects of psychrotrophic bacteria on milk or to evaluate the efficacy of control measures. However, recent findings derived from the application of molecular biological techniques have exposed a number of deficiencies in our knowledge of the biology of milk-associated psychrotrophs. Furthermore, it has been revealed that microbe to microbe communication plays a significant role in determining both the identities and the extent to which different groups of microbes develop during cold storage. The application of molecular identification methods has exposed errors in the classification of members of the genus Pseudomonas isolated from cold stored milk and has stimulated a reevaluation of the presumed status of $P$. fluorescens as the predominant milk-associated psychrotrophic species. This article presents a succinct review of data from studies on psychrotrophic bacteria in milk, some of which contest established theories in relation to the microbiology of cold stored raw milk, and poses the question: how much do we really know?
\end{abstract}

Key words: microbiology, Pseudomonas, dairy products, microbial identification.

\section{Introduction}

The term psychrotrophs (also denominated psychrotolerant) refers to microorganisms that have the ability to grow at low temperatures but have optimal and maximal growth temperatures above 15 and $20{ }^{\circ} \mathrm{C}$, respectively (Moyer and Morita, 2007). This characteristic makes these microbes especially significant with regard to food spoilage and safety, given that the storage of many foods at cold temperatures is a routine practice during production, transportation, processing and post-purchase (Beales, 2004; Russell, 2002).

Raw milk provides a physicochemical environment that is favourable for the multiplication of a broad spectrum of microorganisms, including a range of psychrotrophic bacterial species (predominantly members of the genus Pseudomonas) that contaminate milk during collection and/or processing (Mcphee and Griffiths, 2011; Pinto et al., 2006; Sørhaug and Stepaniak, 1997).

Although the pasteurisation of raw milk decreases its microbial load, the efficiency of the process and the resulting quality of the dairy products are directly influenced by the microbiological quality of the raw milk (Nörnberg et al., 2010). Rigorous hygiene standards employed to reduce the possibility of exogenous contamination coupled with low storage temperatures to control the growth of mesophilic organisms are essential components of the microbial control strategies employed with raw fluid milk (Barbano et al., 2006). Approaches including enclosed pipeline milk systems, better sanitary design of equipment, cleaner cows, and more effective "cleaning in place" coupled with the rapid cooling of raw milk using in-line plate coolers prior to 
storage in bulk tanks have been shown to reduce the growth of contaminating bacteria (Barbano et al., 2006).

The presence and subsequent replication of populations of psychrotrophs may lead to the spoilage of milk (Beales, 2004; Nörnberg et al., 2010; Pinto et al., 2006). Because the economic impact of this group of microbes upon the global dairy industry is substantial, psychrotrophic bacteria have been and continue to be studied extensively with the main objectives of developing effective control measures and establishing regulations to ensure the quality and safety of milk and dairy products (Mcphee and Griffiths, 2011).

Despite the existence of an extensive body of published data, based on the results of recent studies it would be fair to state that numerous gaps exist in our understanding of the biology of the psychrotrophic bacteria of importance for the dairy industry. The continued development of molecular tools for bacterial identification and their application to the analysis of microbial population structures and ecology in milk and dairy products has revealed the presence of psychrotrophic bacteria undetected by the use of traditional culture-based approaches (Almeida and Araujo, 2013; Marchand et al., 2009b; Raats et al., 2011). Similarly, molecular methods have highlighted discrepancies in the identification of the psychrotrophic species associated with the spoilage of cold stored milk, particularly with regard to the taxonomically complex genus Pseudomonas (Mcphee and Griffiths, 2011).

The majority of studies on milk-associated psychrotrophs have focused on individual isolates grown as planktonic cultures (readily culturable). However, there is an increasing recognition that such approaches overlook potential interactions and cross-talk between different species of psychrotrophic bacteria, many of which are non-culturable, that are present within the biofilms that develop in milk storage and processing environments and that may exert an influence on milk quality and safety (Cleto et al., 2012; Marchand et al., 2012).

This current mini-review sought to collate and evaluate the findings of recent studies on psychrotrophic bacteria of importance to the dairy industry and to demonstrate that the activities of psychrotrophic bacteria in milk are more extensive and more complex than was previously thought.

\section{Biochemical Basis for Psychrotrophic Growth}

Temperatures influence bacterial growth rates by affecting the conformation of cellular macromolecules and other constituents, thereby determining the rates of intracellular enzymatic reactions that are crucial for viability (Beales, 2004; Fonseca et al., 2011; Russell, 2002). Hence, the adaptation of the cell to low temperatures requires enzymes that are active in this condition (Chattopadhyay, 2006).

Under low temperature growth conditions psychrotrophic bacteria synthesise phospholipids and neutral lipids containing increased proportions of unsaturated fatty acids, resulting in a reduction in the melting point of the lipids. This phenomenon serves to maintain their fluidity, thus allowing the continued functionality, solute transport, secretion of extracellular enzymes and fluidity of the membrane (Beales, 2004; Jay, 2005)

Indeed, transcriptomic analysis of Pseudomonas putida strain KT2440 revealed that the expression of at least 266 genes (nearly 5\% of the genome) was modified during low temperature growth in comparison to cells grown at $30^{\circ} \mathrm{C}$. Several of these changes seemed to be directed towards neutralising problems created by low temperatures, such as increased protein misfolding, increased stability of DNA/RNA secondary structures, reduced membrane fluidity and reduced growth rates (Fonseca et al., 2011).

\section{Psychrotrophic Bacteria in Milk}

Refrigeration alone or in combination with other methods such as the addition of preservatives is the most commonly used means of preserving food, including milk and dairy products (Beales, 2004). The current trend in the dairy industries is to reduce the frequency of milk collection; thus, the refrigerated storage of milk has been lengthened from two to five days prior to heat treatment (O'brien and Guinee, 2011). This practice has been stimulated in part by a desire for a 5-day work week and in response to a decreased milk supply at certain times of the year (Mcphee and Griffiths, 2011).

The procedure of cooling and the subsequent refrigerated storage of raw milk effectively controls the development of populations of mesophilic spoilage organisms while at the same time providing a selective advantage for the growth of psychrotrophic bacteria (Barbano et al., 2006; De Jonghe et al., 2011; Samarzija et al., 2012). According to Sørhaug and Stepaniak (1997) and Mcphee and Griffiths (2011), the cultivable psychrotrophic bacteria in milk are represented predominantly by Gram-negative genera including Pseudomonas, Achromobacter, Aeromonas, Serratia, Alcaligenes, Chromobacterium and Flavobacterium spp., and at much lower numbers by Gram-positive genera including Bacillus, Clostridium, Corynebacterium, Streptococcus, Lactobacillus and Microbacterium spp.

Interestingly, milk freshly drawn from the udder often does not contain detectable populations of culturable psychrotrophic bacteria. However, these populations develop over time in virtually all cold stored raw milk, a feature that reduces the normal refrigerated storage life to less than $5 \mathrm{~d}$ (Chen et al., 2003; Ma et al., 2003; Mcphee and Griffiths, 2011; Raats et al., 2011). The average counts of psychrotrophic aerobic bacteria in milk silos at several dairies in southwest Scotland were reported to be $1.3 \times 10^{5}$ cfu $\mathrm{mL}^{-1}$. The majority of the bacteria present were Pseudomonads $(70.2 \%)$, but Enterobacteriaceae (7.7\%), Gram- 
positive bacteria $(6.9 \%)$, and other Gram-negative, rodshaped organisms were also isolated (Mcphee and Griffiths, 2011). Following storage for a further $48 \mathrm{~h}$ at $6^{\circ} \mathrm{C}$, the psychrotrophic counts increased by two log cycles to $1.3 \times 10^{7} \mathrm{cfu} \mathrm{\textrm {mL } ^ { - 1 }}$.

In addition to growing at low temperatures, a variety of psychrotrophic bacterial species (primarily represented by pseudomonads) found in raw milk produce heat-stable proteases (Liu et al., 2007) and lipases (Chen et al., 2003), generally during the late $\log$ or early stationary growth phases when the cell density is high. Many of the produced enzymes retain significant activity after pasteurisation $\left(72-75{ }^{\circ} \mathrm{C} / 15-20 \mathrm{~s}\right)$ and even UHT treatment (130-150 $\left.{ }^{\circ} \mathrm{C} / 2-4 \mathrm{~s}\right)$, and may subsequently degrade proteins and fats present in the processed products (Barbano et al., 2006; De Jonghe et al., 2011; Dunstall et al., 2005).

A reduction in cheese yield and tainting are the two most frequently reported negative effects in cheese production that are attributed to psychrotrophic-derived enzymes (Mcphee and Griffiths, 2011). Less frequently reported effects include the alteration of starter activity and/or growth rates and rennet coagulation times (Datta and Deeth, 2001; Mankai et al., 2012). Reduced yields in cheese production occur mainly because soluble casein degradation products (peptides and amino acids) may be lost into the whey instead of forming part of the curd (Mcphee and Griffiths, 2011). The tainting problems are due to the action of proteases, which generate bitter flavours, and lipases, which hydrolyse milk fat yielding free fatty acids (FFAS) and generate strong flavours that in the majority of cases are considered undesirable (Deeth, 2006; Mankai et al., 2012).

'Age gelation' of UHT milk is an irreversible phenomenon characterised by a change in the physical state that is manifested by a rise in viscosity of more than $10 \mathrm{mPa} . \mathrm{S}$ (at $20^{\circ} \mathrm{C}$ ), followed by the formation of a gel and loss of fluidity (Datta and Deeth, 2001). According to Sørhaug and Stepaniak (1997), a psychrotrophic population of $5.5 \log$ cfu $\mathrm{mL}^{-1}$ in raw milk causes UHT milk gelation after 20 weeks of storage, while populations between 6.9 and 7.2 logs will cause the same effect between 2 and 10 weeks.

\section{Biofilm Formation}

The procedures of cooling and refrigeration of milk are not guarantees of quality. The first point of control is to ensure that raw milk is obtained under sanitary conditions designed to minimise contamination (Beales, 2004). The second point of control is dependent on the adequate cleaning and disinfection of all of the equipment used for the collection, transport, and storage of refrigerated raw milk. This step is necessary to prevent fouling with milk film, which can support the growth of bacteria as multi-species biofilms that represent a source of contamination for any subsequent batches of milk (Mcphee and Griffiths, 2011; Perin et al., 2012).
Biofilms are surface-associated bacterial communities that are embedded in a matrix of self-produced polymeric substances (EPSs) consisting of nucleic acids, polysaccharides, lipids and proteins resulting from the successful attachment and subsequent growth of microorganisms on a surface (Marchand et al., 2012; Toyofuku et al., 2012). In nature biofilms can be composed of a single species, but more commonly they comprise a consortium of species (Skandamis and Nychas, 2012). The critical stages for biofilm development are adherence, proliferation, and the dispersion phases (Li and Tian, 2012). Each of these stages includes reinforcement by or modulation of the extracellular matrix. However, the functionality of biofilms depends on a complex web of symbiotic interactions and factors, including $\mathrm{pH}$, nutrient availability, quorum sensing molecules, the presence of organic and inorganic compounds and temperature (Bai and Rai, 2011; Oliveira et al., 2010). Biofilms are the predominant form of growth for bacteria in the majority of environments, including food processing settings (Bai and Rai, 2011; Cleto et al., 2012). More recently, the production of spoiling enzymes by bacteria present in biofilms has also been studied (Teh et al., 2014).

Many Pseudomonas species utilise biofilm formation during plant colonisation to enhance persistence, resulting in the production of a variety of biofilm matrix molecules (Mann and Wozniak, 2012). An intriguing feature of milkspoiling Pseudomonas recovered from biofilms is their ability to alter phenotypes via the process of phase variation (Marchand et al., 2012). Through this process, high-frequency phenotypic switching is mediated by mutation, reorganisation, or modification of the genome (Van Den Broek et al., 2005), contributing to the survival of the biofilm population during environmental stresses such as temperature fluctuations and frequent exposure to sanitizers during the cleaning of dairy processing and storage equipment (Marchand et al., 2012). The limited experimental data generated to date indicates that the traditional approach of studying milk spoilage organisms as planktonic monocultures has most likely served to distort and misdirect our understanding of spoilage processes in situ, and future studies would undoubtedly benefit from experimental approaches designed to mimic the biofilms found in bulk storage and processing systems.

\section{Quorum Sensing and Metabolic Regulation}

Bacteria communicate with each other using chemical signalling molecules when specific cell densities are reached via a process termed quorum sensing (Fuqua et al., 1994; Liu et al., 2007). As a consequence of this process gene expression can either be activated or repressed, and the behaviour of populations of single cells are synchronised in a manner similar to multi-cellular organisms (Bai and Rai, 2011; Smith et al., 2004). Cell density-dependent signalling systems in bacteria control a range of phenotypic 
traits, including biofilm development, bioluminescence, cell differentiation, competence for DNA uptake, pigment production, conjugal plasmid transfer, production of degradative extracellular enzymes, sporulation, toxin production and virulence gene expression (Lazdunski et al., 2004; Li and Tian, 2012).

$\mathrm{N}$-acyl-homoserine lactones (AHLs) are quorum sensing signalling molecules that are produced by a wide range of Gram-negative bacteria, including $P$. fluorescens (Cha et al., 1998; Liu et al., 2007). The production of various AHLs in both raw and pasteurised milk by psychrotrophic Pseudomonas spp. indicates that quorum sensing may play a role in the spoilage of milk and dairy products (Pinto et al., 2007). Coincidentally, the production of extracellular proteases in P. fluorescens is associated with the high cell density that is typically encountered towards the end of the exponential phase of growth (Bai and Rai, 2011). The stimulation of protease production by milk-associated strains of P. fluorescens in response to the addition of AHL has been reported (Liu et al., 2007); the authors concluded that the spoiling ability of psychrotrophic $P$. fluorescens was correlated with the ability to produce AHLs, which served to regulate the expression of extracellular proteases.

In contrast, Liu et al. (2006) demonstrated that AHLs did not act as regulators of proteolytic activity during the spoilage of aerobically chill-stored proteinaceous raw foods including milk. In a subsequent study, Pinto et al. (2010) did not detect AHL signals in the supernatants of late-exponential or stationary phase broth cultures of $P$. fluorescens strain 07A isolated from milk. The authors subsequently added synthetic AHLs or bacterial extracts containing natural AHLs to O7A cultures and found no evidence of effects upon either growth or proteolytic activity, suggesting that quorum sensing (at least via AHLs) did not regulate protease production in strain 07A.

The role of AHLs as promoters of biofilm formation in P. fluorescens strain B52 cultures was investigated by Allison et al. (1998). The addition of $N$-acyl-hexanoyl homoserine lactone to fresh growth medium enhanced biofilm production in a manner similar to that observed when supernatants from 2 day old cultures of B52 were employed as the initial growth medium. Interestingly, analysis of the spent medium using an Agrobacter tumefaciens indicator strain failed to detect AHLs. Nevertheless, the authors concluded that $P$. fluorescens was capable of reacting to the presence of short chain (C6) exogenous homoserines, and speculated that strain B52 produced its own signalling molecule that likely possessed a longer $(>\mathrm{C} 8)$ fatty acyl chain that could not be detected in the A. tumefaciens bioassay.

Although quorum sensing signalling molecules have been detected in cold stored milk and milk derivatives, their exact role in the spoilage process is still not clear and further work on this topic is clearly warranted (Bai and Rai, 2011). Specifically, the topic of inter-species communication via broad range signalling molecules (e.g., autoinducer
AI-2 (Skandamis and Nychas, 2012)) has received limited attention to date, but is thought to represent a pivotal process in the development of multi-species biofilms and the coordinated expression of spoilage enzymes ( $\mathrm{Li}$ and Tian, 2012).

\section{Pseudomonas in Milk}

The genus Pseudomonas is the most heterogeneous and ecologically significant group of known bacteria. Owing to the fact that the nutritional requirements of Pseudomonas spp. are very simple, representatives of the genus have been detected in virtually all natural habitats (e.g., soil, house dust, fresh water and clouds), and have also been isolated from clinical instruments, aseptic solutions, cosmetics and medical products (Franzetti and Scarpellini, 2007). As such, it is not surprising that members of the genus Pseudomonas have long been recognised as the predominant group of psychrotrophic bacteria recovered from spoiled refrigerated milk (Chen et al., 2003). Among the pseudomonads, $P$. fluorescens is generally considered to be the principal spoilage agent of stored milk (Mcphee and Griffiths, 2011; Munsch-Alatossava and Alatossava, 2006).

The efficient cold adaption of the psychrotrophic pseudomonads is believed to be linked to the possession of elevated levels (between 59 to $72 \%$ ) of unsaturated lipids in their cell membranes that impart the ability to efficiently maintain membrane functionality (specifically solute transport and the secretion of extracellular enzymes) at refrigeration temperatures (Fonseca et al., 2011; Jay, 2005). Furthermore, these species are able to proliferate in milk, an environment where the concentration of free iron is low, due to the production of the diffusible fluorescent pigment pyoverdine, which acts as a siderophore, allowing the bacteria to effectively sequester iron from lactoferrin (Mcphee and Griffiths, 2011).

De Jonghe et al. (2011) examined the growth of psychrotrophic pseudomonads in raw milk under conditions that simulated prolonged storage (4 days on the farm, 8 hours in transport and 24 hours of storage at the dairy plant) at suboptimal $\left(6^{\circ} \mathrm{C}\right)$ and optimal $\left(4^{\circ} \mathrm{C}\right)$ storage temperatures. The numbers of Pseudomonas were similar during the first $72 \mathrm{~h}$ of storage at either temperature. However, by the end of the experiment, a striking difference of $2 \log$ cfu $\mathrm{mL}^{-1}$ was reported between the optimal and suboptimal storage conditions. Moreover, Pseudomonas counts reached the same levels as the total aerobic plate counts by the end of the experiment $\left(10^{6}\right.$ and $10^{8} \mathrm{cfu} \mathrm{mL}^{-1}$ for optimally and sub-optimally cooled milk, respectively). Unfortunately, direct comparisons between the work of De Jonghe et al. (2011) and similar studies (e.g., Martin et al., 2011) are difficult to perform due to methodological differences and the specific strains investigated. In this context, the importance of the choice of strain was highlighted in the work of Jaspe et al. (1995), which demonstrated that Pseu- 
domonas spp. isolated from milk that had been stored at $7{ }^{\circ} \mathrm{C}$ for three days grew ten times faster at $7{ }^{\circ} \mathrm{C}$, had 1000 -fold more proteolytic activity, and were 280-fold more lipolytic than Pseudomonas spp. isolated from freshly drawn milk.

Phenotypic analysis of microorganisms isolated from raw milk by Mcphee and Griffiths (2011) demonstrated that $P$. fluorescens biovar I (32.1\% of isolates), $P$. fragi (29.6\%), P. lundensis (19.8\%), and P. fluorescens biovar III $(17.3 \%)$ were the most commonly isolated species, while Marchand et al. (2009a) demonstrated that $P$. lundensis and $P$. fragi were the predominant milk spoilers in Belgian raw milk samples.

Similarly, He et al. (2009) found that pseudomonads predominated in cold stored pasteurised milk at 10 and 5 days before expiration as well as on the expiration day, although they also detected significant numbers of Streptococcus spp. and Buttiauxella spp. in all samples. Pseudomonads also predominated in the microbiota cultured from the crevices of cleaned devices sampled at a milk processing plant, demonstrating their potential roles as postcollection contaminants (Cleto et al., 2012). The ability of this group of microbes to resist cleaning is linked to the fact that many species are effective biofilm producers (Bai and Rai, 2011; Simões et al., 2008). The complex and multilayered structures of biofilms allow the bacterial communities to live in a sessile and protected environment. Yet, when population densities in the biofilms become high, bacteria are released into the environment, providing a continuous source of planktonic bacteria capable of replication within milk (Bai and Rai, 2011).

\section{Pseudomonas spp.: Misidentification}

A study of raw milk samples obtained along the cold chain of milk transportation (from farm, trucks, and silos) in Finland demonstrated that the majority (88\%) of the isolated bacteria were psychrotrophic (Munsch-Alatossava and Alatossava, 2006). The authors employed two commercial phenotypic identification systems (API-20NE and BIOLOG GN2) and reported difficulties in obtaining confident identification of many of the isolates. This was particularly the case for fluorescent pigment-producing pseudomonads, where the biochemical results were considered to be doubtful. In view of this controversy, the authors recommended the use of genotypic identification systems in future studies.

A comparative evaluation of phenotypic and genotypic methods for the identification of 102 food-associated psychrotrophic Pseudomonas spp. clearly demonstrated that molecular methods provided superior results (Franzetti and Scarpellini, 2007). In this study, phenotypic data identified the bacteria as $P$. fluorescens or $P$. putida, with a single strain identified as $P$. aeruginosa. In contrast, sequencing of $16 \mathrm{~S}$ rDNA in combination with restriction fragment length polymorphism (RFLP) analyses resulted in the identification of the bacteria as $P$. jessenii, $P$. orientalis, $P$. migulae and P. chicorii, and also confirmed the phenotypic data for the $P$. aeruginosa isolate.

The study of Hantsis-Zacharov and Halpern (2007) evaluated 264 bacteria collected from raw milk during different seasons. They reported the presence of representatives of seven classes of bacteria (Gammaproteobacteria, Bacilli, Actinobacteria, Alphaproteobacteria, Betaproteobacteria, Flavobacteria and Sphingobacteria), with $20 \%$ of the isolates considered to be novel species. Pseudomonas and Acinetobacter were recorded as the predominant genera among the Gram-negatives, with 33 and 29 isolates, respectively. Sequencing of the gene encoding 16S rRNA identified the majority (15) of the isolates as $P$. putida, and demonstrated the presence of the novel milkassociated species $P$. sinxantha, $P$. brenneri and $P$. veronii.

Marchand et al. (2009a) employed a polyphasic approach including molecular methods for the identification of the predominant producers of heat-resistant proteases in raw milk in Belgium. $P$. fragi and $P$. lundensis represented $53 \%$ of the producers of heat-resistant proteases, with $P$. fluorescens representing a minority of the isolates. The authors recommended the increased application of genotypic identification methods to ensure accuracy, and they also called for a revision of the taxonomic status of $P$. fluorescens. Furthermore, they considered it likely that misidentification of many proteolytic isolates as $P$. fluorescens in earlier studies using phenotypic characterisation had led to an overestimation of the importance of this species as a milk spoiler.

A further example of the difficulties associated with the identification of milk spoiling Pseudomonas species was provided by the study of Corrêa et al. (2011). Using phenotypic methods, the authors identified the highly proteolytic Pseudomonas strain 1A4R as either P. asplenii or $P$. jenssenii. The subsequent application of $16 \mathrm{~S}$ rDNA sequencing revealed a level of $99 \%$ nucleotide sequence homology with $P$. koreensis, which forms part of the socalled $P$. jenssenii group. In view of the divergent data, strain 1A4R was classified as a Pseudomonas sp. belonging to the $P$. jenssenii group.

Improvements in identification at the species and sub-species levels should become possible through the use of highly specific typing methods such as the Multilocus Sequence Typing (MLST) scheme developed by Andreani et al. (2014) for the characterisation of the P. fluorescens group. However, it should be noted that the elevated costs of such sequencing-based methods is likely to limit their use, at least in the short term, to academic studies.

\section{Use of Molecular Tools to Elucidate the Ecology of Psychrotrophic Bacteria}

Indigenous bacterial communities in raw milk, including potentially lipolytic and proteolytic psychrotrophs, 
are already present when the milk arrives at the dairy plant, making the rapid and accurate identification of the raw milk microbiota a necessary prerequisite for the elaboration of methods to circumvent spoilage (Van Der Vossen and Hofstra, 1996). Based on the observation that initial psychrotrophic counts of milk are frequently very low (Mcphee and Griffiths, 2011), more sensitive and efficient methods to evaluate the bacterial quality of raw milk are required to identify the causes of reduced shelf life and the deterioration of technological properties of milk during storage (Quigley et al., 2013).

Traditional microbiological approaches to the study of psychrotrophs in milk based on phenotypic characterisation are time consuming, lack discriminatory power and sensitivity and are often ineffective in establishing a causal relationship between the contamination of the finished product and the environmental source (Dogan and Boor, 2003; Rasolofo et al., 2010). Furthermore, the inability to discriminate between closely related organisms can lead to misidentification, and the slow turnaround time of the results makes phenotypic testing useful mainly for retrospective evaluation (Ercolini, 2004; Raats et al., 2011).

Molecular analyses of microbes offer some advantages over phenotypic methods, including speed and the ability to provide precise identification of microorganisms from the genus to the strain level, depending on the system used. The discrimination between subspecies and strains is helpful for investigating the routes and sources of contamination (Ercolini, 2004; Rasolofo et al., 2010). Molecular methods can be culture-dependent (nucleic acids are recovered from cultured microbes) or culture-independent (total bacterial DNA/RNA is extracted directly from an environmental sample, thereby providing information for the components of the microbiota that are unable to grow under laboratory conditions) (Ercolini, 2004; Ercolini, 2013; Quigley et al., 2013; Raats et al., 2011).

The concept of viable but non-culturable (VBNC) bacteria refers to bacteria with metabolic activity and the ability to reproduce under suitable conditions, but which lack the capability to produce visible growth under standard conditions. Interest in the role of VBNC in food spoilage has increased due to the observation that some disinfection procedures such as pasteurisation of milk and chlorination of water can cause bacteria to switch to the VBNC form (Ozcakir, 2007).

High-throughput sequencing of $16 \mathrm{~S}$ rDNA and realtime quantitative PCR (qPCR) analysis were used in combination with flow cytometry to examine the microbial content of raw and pasteurised cow milk (Quigley et al., 2013). In contrast to findings from culture-based studies (Ranieri et al., 2009), the use of culture-independent methods demonstrated that the pasteurisation process resulted in an overall reduction in the number of pseudomonads rather than their complete elimination. Interestingly, the presence of pseudomonads in pasteurised milk has traditionally been considered to be the result of post-pasteurisation contamination (Van Tassell et al., 2012). However, it is worth considering that the survival and subsequent transition from VBNC to fully viable cells may explain, at least in part, the frequent isolation of this genus from pasteurised milk.

Quigley et al. (2011) recently reviewed several culture-dependent and -independent methods applicable to milk and cheese. Among the culture-independent methods, denaturing gradient gel electrophoresis (DGGE) based on the separation of complex mixtures of PCR amplicons of the same size but with different nucleotide sequences has emerged as the most commonly used fingerprinting technique applied to the study of populations of psychrotrophic bacteria associated with milk and dairy products (Ercolini, 2004; Raats et al., 2011; Rasolofo et al., 2010). This technology provides a convenient means to obtain a comprehensive overview of the microbial populations in milk during cold storage, has confirmed the predominance of Pseudomonas spp. in pasteurised milk samples during their shelf life and has revealed a greater level of species diversity among the pseudomonads than had been previously indicated by culture-dependent methods (He et al., 2009; Raats et al., 2011). Furthermore, the application of DGGE to raw milk samples from three farm bulk tanks and three dairy plant silo tanks in Israel clearly demonstrated that refrigeration served to reduce the microbial diversity of raw milk, and showed that the predominance of Pseudomonas species was actually the end result of complex microbial successions that varied depending on the source of the milk (Raats et al., 2011). In the case of farm samples, Grampositive bacteria represented by the classes Actinobacteria and Bacilli predominated at the time of collection and were gradually overgrown by Pseudomonas species. In contrast, dairy plant tank samples were initially dominated by a variety of Gram-negative bacteria belonging to the Gammaproteobacteria class, with Pseudomonas and Acinetobacter species predominating within $48 \mathrm{~h}$ of refrigeration (Raats et al., 2011). The predominance of psychrotolerant members of the class Actinobacter in the farm samples and their presence at lower levels in the silo samples was in agreement with data from DGGE-based examinations of raw milk samples in Canada (Rasolofo et al., 2010) and of raw milk and fresh curd used for Fontina cheese production in Italy (Giannino et al., 2009). Interestingly, cultivable and milk-associated members of this class of bacteria were previously reported to possess the ability to secrete heat-stable proteolytic and lipolytic enzymes (Hantsis-Zacharov and Halpern, 2007). Hence, it is possible that these bacteria may play a role in the spoilage processes during the early stages post-milk collection or may even be involved in the degradation of proteins and fats present in processed dairy products.

An alternative molecular fingerprinting method called random amplified polymorphic DNA-polymerase 
chain reaction (RAPD-PCR) was applied to 66 bacterial isolates from cold stored raw milk prior to nucleotide sequence analysis of the gene encoding the $16 \mathrm{~S}$ ribosomal RNA (Ercolini et al., 2009). In agreement with the results obtained with DGGE, this approach identified Pseudomonas spp. as the most common contaminant, but also identified Hafnia alvei, Serratia marcersens, Citrobacter freundii, Staphylococcus and Lactococcus.

\section{Conclusion}

The role of pseudomonads and primarily $P$. fluorescens as the predominant psychrotrophs associated with the spoilage of cold stored milk and milk-derived products has been established through a long history of culture-based studies. However, these types of studies are often limited to the phenotypic characterisation of the most abundant isolates following their isolation as pure cultures. The validity of this approach has been questioned by recent findings using nucleotide sequence-based identification methods, which have shown that the diversity of Pseudomonas species involved in milk spoilage is much wider than was previously thought. Moreover, real time molecular analysis of microbial communities has shown that psychrotrophic species other than Pseudomonas predominate in milk during the early stages post-collection, and that the activities of those communities may play a role in the subsequent spoilage of milk.

The emergence of molecular methods has provided a new means with which to obtain an accurate global view of the microbial communities in milk. The application of these methods has revealed potential roles for genera other than Pseudomonas as important agents of milk spoilage at refrigeration temperatures. Moreover, it is likely that the mixed bacterial populations that are often present in the form of biofilms collaborate in the spoilage process via mechanisms based on quorum sensing. The practical implications for these essentially preliminary findings have yet to be elucidated. However, it is clear that the continued study of milk-associated psychrotrophs is required and should be encouraged in order to enhance and improve existing control methods and to help ensure the quality and safety of milk and milk-derived foodstuffs.

\section{References}

Allison DG, Ruiz B, Sanjose C et al. (1998) Extracellular products as mediators of the formation and detachment of Pseudomonas fluorescens biofilms. FEMS Microbiol Lett 167:179-184.

Almeida LA, Araujo R (2013) Highlights on molecular identification of closely related species. Infect Genet Evol 13:67-75.

Andreani NA, Martino ME, Fasolato L et al. (2014) Tracking the blue: a MLST approach to characterise the Pseudomonas fluorescens group. Food Microbiol 39:116-126.

Bai AJ, Rai VR (2011) Bacterial quorum sensing and food industry. Compr Rev Food Sci F 10:183-193.
Barbano DM, Ma Y, Santos MV (2006) Influence of raw milk quality on fluid milk shelf life. J Dairy Sci 89:E15-E19.

Beales N (2004) Adaptation of microorganisms to cold temperatures, weak acid preservatives, low $\mathrm{pH}$, and osmotic stress: a review. Compr Rev Food Sci F 3:1-20.

Cha C, Gao P, Chen YC et al. (1998) Production of acyl-homoserine lactone quorum-sensing signals by gram negative plant-associated bacteria. MPMI 11:1119-1129.

Chattopadhyay MK (2006) Mechanism of bacterial adaptation to low temperature. J Biosci 31:157-165.

Chen L, Daniel RM, Coolbear T (2003) Detection and impact of protease and lipase activities in milk and milk powders. Int Dairy J 13:255-275.

Cleto S, Matos S, Kluskens L et al. (2012) Characterization of contaminants from a sanitized milk processing plant. PLoS ONE 7:1-8.

Corrêa APF, Daroit DJ, Velho RV et al. (2011) Hydrolytic potential of a psychrotrophic Pseudomonas isolated from refrigerated raw milk. Braz J Microbiol 42:1479-1484.

Datta N, Deeth HC (2001) Age Gelation of UHT Milk - A Review. Food Bioprod Process 79:197-210.

De Jonghe V, Coorevits A, Van Hoorde K et al. (2011) Influence of storage conditions on the growth of Pseudomonas species in refrigerated raw milk. Appl Environ Microbiol 77:460470.

Deeth HC (2006) Lipoprotein lipase and lipolysis in milk. Int Dairy J 16:555-562.

Dogan B, Boor KJ (2003) Genetic diversity and spoilage potentials among Pseudomonas spp. isolated from fluid milk products and dairy processing plants. Appl Environ Microbiol 69:130-138.

Dunstall G, Rowe MT, Wisdom GB et al. (2005) Effect of quorum sensing agents on the growth kinetics of Pseudomonas spp. of raw milk origin. J Dairy Res 72:276-280.

Ercolini D (2004) PCR-DGGE fingerprinting: novel strategies for detection of microbes in food. J Microbiol Methods 56:297314.

Ercolini D (2013) High-throughput sequencing and metagenomics: moving forward in the culture-independent analysis of food microbial ecology. Appl Environ Microbiol 79:31483155.

Ercolini D, Russo F, Ferrocino I et al. (2009) Molecular identification of mesophilic and psychrotrophic bacteria from raw cow's milk. Food Microbiol 26:228-231.

Fonseca P, Moreno R, Rojo F (2011) Growth of Pseudomonas putida at low temperature: global transcriptomic and proteomic analyses. Environ Microbiol Rep 3:329-339.

Franzetti L, Scarpellini M (2007) Characterisation of Pseudomonas spp. isolated from foods. Ann Microbiol 57:39-47.

Fuqua WC, Winans SC, Greenberg EP (1994) Quorum sensing in bacteria: the LuxR-LuxI family of cell density-responsive transcriptional regulators. J Bacteriol 176:269-275.

Giannino ML, Marzotto M, Dellaglio F et al. (2009) Study of microbial diversity in raw milk and fresh curd used for Fontina cheese production by culture-independent methods. Int $\mathrm{J}$ Food Microbiol 130:188-195.

Hantsis-Zacharov E, Halpern M (2007) Culturable psychrotrophic bacterial communities in raw milk and their proteolytic and lipolytic traits. Appl Environ Microbiol 73:7162-7168.

He H, Dong J, Lee CN et al. (2009) Molecular analysis of spoilage-related bacteria in pasteurized milk during refrigeration 
by PCR and denaturing gradient gel electrophoresis. J Food Prot 72:572-577.

Jaspe A, Oviedo P, Fernandez L et al. (1995) Cooling raw milk: change in the spoilage potential of contaminating Pseudomonas. J Food Prot 58:915-921.

Jay MJ (2005) Microbiologia de Alimentos. 6 ed. Artmed, Porto Alegre, 711 p. I

Lazdunski AM, Ventre I, Sturgis JN (2004) Regulatory circuits and communication in Gram-negative bacteria. Nat Rev Microbiol 2:581-592.

Li Y-H, Tian X (2012) Quorum sensing and bacterial social interactions in biofilms. Sensors 12:2519-2538.

Liu M, Gray JM, Griffiths MW (2006) Occurrence of proteolytic activity and $\mathrm{N}$-acyl-homoserine lactone signals in the spoilage of aerobically chill-stored proteinaceous raw foods. J Food Prot 69:2729-2737.

Liu M, Wang H, Griffiths M (2007) Regulation of alkaline metalloprotease promoter by $\mathrm{N}$-acyl homoserine lactone quorum sensing in Pseudomonas fluorescens. J Appl Microbiol 103:2174-2184.

Ma Y, Barbano DM, Santos M (2003) Effect of CO2 addition to raw milk on proteolysis and lipolysis at $4{ }^{\circ} \mathrm{C}$. J Dairy Sci 86:1616-1631.

Mankai M, Boulares M, Ben Moussa O et al. (2012) The effect of refrigerated storage of raw milk on the physicochemical and microbiological quality of Tunisian semihard Gouda-type cheese during ripening. Int J Dairy Technol 65:250-259.

Mann EE, Wozniak DJ (2012) Pseudomonas biofilm matrix composition and niche biology. FEMS Microbiol Rev 36:893916.

Marchand S, De Block J, De Jonghe V et al. (2012) Biofilm formation in milk production and processing environments; influence on milk quality and safety. Compr Rev Food Sci F 11:133-147.

Marchand S, Heylen K, Messens W et al. (2009a) Seasonal influence on heat-resistant proteolytic capacity of Pseudomonas lundensis and Pseudomonas fragi, predominant milk spoilers isolated from Belgian raw milk samples. Environ Microbiol 11:467-482.

Marchand S, Vandriesche G, Coorevits A et al. (2009b) Heterogeneity of heat-resistant proteases from milk Pseudomonas species. Int J Food Microbiol 133:68-77.

Martin NH, Ranieri ML, Murphy SC et al. (2011) Results from raw milk microbiological tests do not predict the shelf-life performance of commercially pasteurized fluid milk. J Dairy Sci 94:1211-1222.

Mcphee JD, Griffiths MW (2011) Psychrotrophic bacteria Pseudomonas spp. In: John, W.F. (Ed). Encyclopedia of Dairy Sciences. Second Edition. Academic Press, San Diego, pp 379-383.

Moyer CL, Morita RY (2007) Psychrophiles and psychrotrophs. In: Morita RY (ed.) Encyclopedia of Life Sciences. John Wiley \& Sons Ltd, Chichester. pp 1-6.

Munsch-Alatossava P, Alatossava T (2006) Phenotypic characterization of raw milk-associated psychrotrophic bacteria. Microbiol Res 161:334-346.

Nörnberg MFBL, Friedrich RSC, Weiss RDN et al. (2010) Proteolytic activity among psychrotrophic bacteria isolated from refrigerated raw milk. Int J Dairy Technol 63:41-46.

O’brien B, Guinee TP (2011) Milk Seasonal effects on processing properties of cows' milk. In: Fuquay, J. W. (Ed) Encyclope- dia of Dairy Sciences. Second Edition. Academic Press, San Diego, pp 598-606.

Oliveira MMM, Brugnera DF, Piccoli RH (2010) Biofilmes microbianos na indústria de alimentos: Uma revisão. Rev Inst Adolfo Lutz 69:277-284.

Ozcakir O (2007) Viable but non-culturable form of bacteria. Mikrobiyol Bul 41:477-484.

Perin LM, Moraes PM, Almeida MV et al. (2012) Interference of storage temperatures in the development of mesophilic, psychrotrophic, lipolytic and proteolytic microbiota of raw milk. Semin-Cienc Agrar 33:333-342.

Pinto CLO, Martins ML, Vanetti MCD (2006) Qualidade microbiológica de leite cru refrigerado e isolamento de bactérias psicrotróficas proteolíticas. Food Sci Technol (Campinas) 26:645-651.

Pinto UM, Costa ED, Mantovani HC et al. (2010) The proteolytic activity of Pseudomonas fluorescens $07 \mathrm{~A}$ isolated from milk is not regulated by quorum sensing signals. Braz J Microbiol 41:91-96.

Pinto UM, De Souza Viana E, Martins ML et al. (2007) Detection of acylated homoserine lactones in gram-negative proteolytic psychrotrophic bacteria isolated from cooled raw milk. Food Control 18:1322-1327.

Quigley L, McCarthy R, O'Sullivan O et al. (2013) The microbial content of raw and pasteurized cow milk as determined by molecular approaches. J Dairy Sci 96:4928-4937.

Quigley L, O'Sullivan, Beresford TP et al. (2011) Molecular approaches to analysing the microbial composition of raw milk and raw milk cheese. Int J Food Microbiol 150:81-94.

Raats D, Offek M, Minz D et al. (2011) Molecular analysis of bacterial communities in raw cow milk and the impact of refrigeration on its structure and dynamics. Food Microbiol 28:465-471

Ranieri ML, Huck JR, Sonnen M et al. (2009) High temperature, short time pasteurization temperatures inversely affect bacterial numbers during refrigerated storage of pasteurized fluid milk. J Dairy Sci 92:4823-4832.

Rasolofo EA, St-Gelais D, Lapointe G et al. (2010) Molecular analysis of bacterial population structure and dynamics during cold storage of untreated and treated milk. Int J Food Microbiol 138:108-118.

Russell NJ (2002) Bacterial membranes: the effects of chill storage and food processing. An overview. Int J Food Microbiol 79:27-34.

Samarzija D, Zamberlin S, Pogacic T (2012) Psychrotrophic bacteria and their negative effects on milk and dairy products quality. Mljekarstvo 62:77-95.

Simões M, Simões LC, Vieira MJ (2008) Physiology and behavior of Pseudomonas fluorescens single and dual strain biofilms under diverse hydrodynamics stresses. Int J Food Microbiol 128:309-316.

Skandamis PN, Nychas GJ (2012) Quorum sensing in the context of food microbiology. Appl Environ Microbiol 78:54735482 .

Smith JL, Fratamico PM, Novak JS (2004) Quorum sensing: a primer for food microbiologists. J Food Prot 67:1053-1070.

Sørhaug T, Stepaniak L (1997) Psychrotrophs and their enzymes in milk and dairy products: quality aspects. Trends Food Sci Tech 8:35-41. 
Teh KH, Flint S, Palmer J et al. (2014) Biofilm - An unrecognised source of spoilage enzymes in dairy products? Int Dairy $\mathrm{J}$ $34: 32-40$.

Toyofuku M, Roschitzki B, Riedel K et al. (2012) Identification of proteins associated with the Pseudomonas aeruginosa biofilm extracellular matrix. J Proteome Res 11:4906-4915.

Van Den Broek D, Chin-a-Woeng TFC, Bloemberg GV et al. (2005) Molecular nature of spontaneous modifications in gacS which cause colony phase variation in Pseudomonas sp. strain pcl1171. J Bacteriol 187:593-600.
Van Der Vossen JMBM, Hofstra H (1996) DNA based typing, identification and detection systems for food spoilage microorganisms: development and implementation. Int J Food Microbiol 33:35-49.

Van Tassell JA, Martin NH, Murphy SC et al. (2012) Evaluation of various selective media for the detection of Pseudomonas species in pasteurized milk. J Dairy Sci 95:1568-1574.

Associate Editor Elaine Cristina Pereira De Martinis

All the content of the journal, except where otherwise noted, is licensed under a Creative Commons License CC BY-NC. 